\title{
THE DESIGN OF SYSTEMS FOR LEARNING AND WORKING IN LIBRARIANSHIP
}

\author{
Alex Birchall and Roy Rada. \\ Department of Computer Science \\ Liverpool University \\ Liverpool L8 0SY \\ England
}

\begin{abstract}
The paper presents a philosophy and theory for the design of a system that would mediate between the librarian as a knowledge worker and the library as a learning organization. It does this by combining Activity Theory and Ecological Interface Design.. The task to be supported is that of classification. The hypothesis is that the task of library classification can be supported by using the surrounding organization as an interactive learning environment, as the process of organizational learning depends on an appreciation of the cognitive process of classification.

Introduction
\end{abstract}

The title of this paper begs a question: Why do we need systems for learning and working in librarianship? In the first part of this paper it is suggested why we do, introducing the emerging models of the knowledge worker and the learning organization. Then, a philosophy and theory of design is put forward that would support the development of such systems. These derive from two established areas of research: Activity Theory and Ecological Interface Design. It is suggested that the synergism between these two approaches to design can be fruitfully combined. Finally, a first attempt is made at applying the principals. Learning and Working with(in) the Electronic Text Throughout history, information technology has been associated with the transformation of thought and culture. The technologies that people use to manage knowledge have profound effects both on social organization and individual cognition. This has been demonstrated by research into the effects of 
literacy (Goody 1977; Ong 1982; Hoskin and Macve 1986). Similarly dramatic transformations have long been foreseen as resulting from computer and communications technologies ( $c f$. McLuhan, 1964; Boulter 1984; and so on). One such transformation is a new conception of the relationship between work and learning. The increasing "systemness" of society (Beniger 1986) is leading to the development of new types of work organization (Hirschhorn 1984; Heydebrand 1989; Engeström 1990). These organizations are formed of decentralized work teams having overall responsibility for their own work. They develop and utilize high-level theoretical and conceptual instruments in everyday labour. There is a growing importance of the activities of design and planning. In such organizations, working and learning are explicitly recognized as inseparable. Working is learning and people are paid to do it. In the flexible specialization hypothesis of Piore and Sabel (1984), information technology facilitates a new kind of craft production, similar to but different from preindustrial craft production. That librarianship might be moving towards a type of craft production reminiscent of a previous era is suggested by the observations of McLuhan in Understanding Media (1964) and Ong in Orality and Literacy (1982). Ong saw the emergence of a "secondary orality" that shares with the "primary orality" of preliterate cultures a "participatory mystique", a "communal sense", a "concentration on the present moment", and a reliance on the use of formulas. However, it contrasts with primary orality in its qualities of deliberateness and self-consciousness, and it is based firmly on the use of writing and print (Ong 1982, p 136). The move towards the "special librarianship" model in response to the increasing automation of the technical core of librarianship (Jones 1984) is being intensified by research into communications in work organizations on how different types of knowledge, especially mental models, can be captured and stored (e.g., Moulin 1990; Meyer 1990; Carlson and Ram 1990; Brown 1991; Boland et. al. 1992, 1994).

Huber (1990) theorized that one of the beneficial effects of advanced information technologies on organizational design, intelligence, and decision-making would 
be the development of more effective "organizational memories." Organizational memory is central to the learning organization. The technological realization of organizational memory is underway in the development of the "Corporate Knowledge Repository" and the "Information Warehouse". Several companies, especially retailers, now have them (Gooding 1995). "Groupware" products, such as Lotus Notes, are explicitly being used to develop learning organizations. All these developments transform the organization into an "electronic text" (Zuboff 1988).

\section{Managing the Electronic Text}

The electronic text as organizational memory supports both individual and collective learning. But the phenomenon of collective learning is a disputed subject. It is not known exactly what the processes of collective learning are, nor whether, if they do exist, information technology can support them.

There is a growing consensus that the process of organizational learning is intimately connected with an organization's culture (Schein 1985). However, exactly what organizational culture is and how individual behaviour relates to it is are questions of ongoing research (Whyte 1991; Kim 1994). It does seem that organizations evidence learning that cannot be accounted for by environmental influence, nor by individuals' learning (Argote 1993).

The essential difference between a conventional text and the electronic text of a "virtual" organization is that the former is a closed system while the latter is an open system under constant reconstruction by organizational members. Connerton (1989) argues that the processes that serve to ensure the connection between the past and the present of societies are habitual, ritualistic performances. These are non-textual and non-cognitive . Zuboff (1988) showed how the "action-centred skills" involved in these performances are destroyed by incorporation in the electronic text.

The destruction of action-centred skills is also a destruction of meaning. Thus, the (re)construction of meaning becomes the key cognitive ability in working with the electronic text. And the construction of meaning from the electronic text 
depends upon the intellective skills that are the basis upon which data are translated into meaningful information, and finally into knowledge. These are the skills generally attributed to the knowledge worker. It is argued here that they are the conventional skills of the librarian. Just as personal computing has integrated information management into the work of knowledge workers, so it necessitates the development of what used to be the skills of the librarian. However, the difference is that the librarian has had the explicit task of developing classifications of knowledge so that people can communicate with a shared understanding.

The (re)Construction of Meaning in Information Systems Development. Intellective skills, as defined by Zuboff (1988, p. 76) involve the competencies of abstraction, explicit inference, and procedural reasoning. These are the competencies that are normally associated with formal schooling. It has generally been assumed that they enable generalization and the transfer of knowledge from one domain to another. In educational research, this ability to "learn how to learn"; has been termed "metacognition" (Brown, 1992).

However, the nature of metacognitive skills is disputed, particularly their contextindependence. Research in sociocultural psychology seems to demonstrate the contextually-bound nature of learning (Scribner and Cole 1981; Rogoff 1984; Lave 1991). This research disputes the individualistic, information-processing conception of metacognitive skills, on the basis of which it had been assumed that the generalization of learning between domains of activity takes place entirely within the individual's brain, which acts like the central processing unit in a computer. This is replaced with a model of learning that emphasizes its situatedness.

The problem for the advocates of "situated learning" is to explain exactly how it is that transfer of learning between domains actually does take place. The answer is that transfer takes place in the process of the construction of meaning. The construction of meaning is also essentially a social phenomenon (Zuboff 1988). It is a social skill that is not so much concerned with problem-solving, as with 
problem-setting. This ability is a stage of development beyond that of Formal Operations as defined by Piaget (Basseches 1984).

It is termed "expansive learning" and given a conceptual framework by Engeström (1987). Expansive learning occurs when the individual forgoes conscious control of actions and somehow taps in to the distributed activity. "Traditional conceptions of expansive personality and social development picture expansion as an uncontrollable, spontaneous phenomenon." However, Engeström hypothesizes that this type of learning is currently emerging as a consciously controlled phenomenon as a result of changes in various field of human activity.

\section{Activity Theory: Modelling Reality as Ongoing Creation}

To attempt to investigate scientifically how it is that the individual is able to access distributed activity, Engeström (1987) formulates a basic model of how the individual is related to society. This model draws on a tradition of systems thinking developed in the works of Hegel, Darwin, and Marx. The basic insight was the conception of man as a systemic and historical being. Engeström (1987, 37-92) traces this insight in the work of twentieth century thinkers. Firstly, from the work in semiotics of C. S. Peirce and in epistemology of Karl Popper, he takes the idea of knowledge and meaning as mediated construction. Secondly, from the social psychological work of G. H. Mead is taken the idea of the social, interactive, symbol-mediated construction of reality. Finally, from the sociocultural work of Vygotsky and Leont'ev he takes the idea of human activity based on material production, mediated by technical and psychological tools as well as by other human beings. Then, arguing from speculations in evolutionary genetics, Engeström (1987, p. 78) developed a basic model of specifically human activity (see Fig. 1).

Figure 1: The basic structure of human activity (from Engeström 1987, 78) $(5 \mathrm{~K})$ The model serves to specify the relationship between the mediating elements in the individual's relationship with the world. It enlarges on the idea of the mediated nature of the relationship between subject and object to include in this mediation 
the influence of culture, represented by "community", "rules" and "division of labour". The model also specifies the relationships between the various elements. Its purpose is to direct our attention to the factors that need to be taken into account when analyzing organizations (Holt and Morris 1993) or planning organizational change (Engeström 1990, pp. 69-226).

Activity systems have a "zone of proximal development", defined as the "distance between the present everyday actions of the individuals and the historically new form of the societal activity that can be collectively generated as a solution to the double-bind potentially embedded in everyday actions." (Engeström 1987, p. 174). This has a phase-structure (see Fig. 2)

Figure 2: The phase structure of the zone of proximal development (Engeström 1987, p. 189) (7K)

The impetus to change arises from systemic contradictions, of which there are four types

1. Primary - within each constituent component of the activity;

2. Secondary - between the constituent components of the activity;

3. Tertiary - between the activity itself and a "culturally more advanced" form of the activity;

4. Quaternary - between the central activity and its neighbouring activities.

It is tertiary contradictions that actually precipitate evolution. To consciously bring this about, contradictions need to be made explicit and resolved with the use of "springboards", or "new specific instrument[s] ... for breaking the constraints and for constructing a new general model for the subsequent activity" (Engeström 1987, 189).

Engeström's formulation of Activity Theory is useful in providing guidelines for organizational analysis and the derivation of specifications for information systems (Kuutti and Arvonen 1992; Favorin and Kuutti 1994; Kuutti and Virkunnen 1995). However, it does not provide guidelines for translating these specifications into interface design. For this purpose, it is instructive to turn to 
Ecological Interface Design (EID), which share with Activity Theory the same, non-dualist philosophical tradition

Ecological Interface Design: Representing the Electronic Text

Ecological interface Design is so-called because it derives theoretically from the Ecological Psychology formulated by J. J. Gibson (Vicente and Rasmussen 1992).

In contrast to the Vygotskyian idea that our perception of the world is always mediated, Gibson formulated the idea of direct perception in opposition to the conventional model of perception (Gibson 1979). In this latter model, the organism picks up random information from the environment through its sensorium, and this information is then transmitted to the brain where it only becomes meaningful through a process of representation in cognitive structures. Gibson hypothesized that this process did not have to take place: through the mutual evolution of organism and environment, the senses had become capable of picking up meaningful information directly from the environment without having to relay the information for processing in the brain.

However, Gibson was forced to the conclusion that not all perception is direct. The problem was how to account for perception via representations such as language, money, and number. Thus, he allowed for the existence of indirect perception. Yet he was adamant that indirect perception could be explained without reverting to the information-processing model.

According to Gibson (1979), direct perception is made possible by the affordances of the environment. Affordances are the action possibilities of the real world. They are fundamentally integrated in the natural perceptual process. "The perceiving of an affordance is not a process of perceiving a value-free physical object to which meaning is somehow added....: it is a process of perceiving a value-rich ecological object." (p. 140). "An affordance is an invariant combination of variables" (p. 134). The reason that affordances are perceived is due to a process of resonance. 
Rasmussen et al (1994, p 116) argue "that the theory of direct perception is equally as applicable in high-technology work domains as it is to the natural environment and to high level problem solving mediated through a computer screen." The world is composed of a hierarchy of affordances (Gibson 1979, p. 137). The levels of the hierarchy are related through means-ends connections.

Ecological Interface Design seeks to represent the affordances of the environment through the abstraction hierarchy .

\section{Building the Electronic Text}

It was proposed to test the workability of these principles in the design of a system to support work and learning in a library. The hypothesis was that a system to support library classification could also support organizational learning, by providing users with the tools for modelling knowledge. Thus, the organization itself would become an Interactive Learning Environment (Young 1993).

The Identification of Objects Using Activity Theory

On the basis of his model of expansive learning, Engeström (1987, p. 322-323) developed a model of "expansive developmental research". This cyclic model involves five steps. Together, they provide guidelines for arriving at a specification for an information system.

The first step is to gain phenomenological insight into the nature of the activity's discourse and the problems as experienced by those involved in the activity. This enables a delineation of activity system under investigation. It is here that the primary contraditions may be identified.

The second step consists of "rigorous analyses of the activity system". Three types of analyses are enumerated: 1) Identifying and analyzing the successive developmental phases of the activity system. The secondary contradictions must be identified that lead from one developmental phase to another. 2) Identification of the concepts and models used in the activity in its different developmental stages. 3) Actual investigation of how the activity is carried out in an existing environment. 
The third step involves the formation of new instruments. These should provide the means for resolving the secondary contradictions identified previously. The fourth step is the practical application of the new instruments. The fifth and final step is reporting and assessing the outcomes of expansive research..

This research does not follow through the whole cycle of expansive research. Its goal is to reach the third step, that of the formation of new instruments that can expose and help to resolve the secondary contradictions.

The First Step

Phenomenological insight was provided by the researcher's background in librarianship. He had studied librarianship in higher education and had worked in various libraries.

The understanding thus gained led to the identification of the principal task of the librarian: The conjoining of people and knowledge. The central way in which this is achieved is through the classification of knowledge. The public librarian has to tailor a universal classification to the needs of the users.

\section{The Second Step}

In order to ground the research in reality and gain insight into the classification task as it was actually practiced by working librarians, a participant observation study was conducted in Liverpool City Public Library. This involved the researcher in spending two days a week working in the classification and cataloguing team in the technical services section of the library. At this stage also insight was gained into the secondary contradictions.

\section{The Third Step}

The third step involved taking the data gathered in the first two steps and translating them into the design for "new instruments". A first task was to model the primary and secondary contradictions (see Fig. 3). In the figure, primary contradictions occur within the components of the activity; secondary contradictions occur between the components of the activity (they are represented by the jagged lightning bolts). 
Figure 3: Inner contradictions of the work activity of librarians (8K)

The Representation of Objects in the Abstraction Hierarchy

The task now is to map the Activity Theory model in terms of an abstraction hierarchy. In the Activity Theory model, the higher levels of abstraction are represented in the elements at the base of the triangle. This constitutes a first pass at identifying the objects to be represented in the interface (see Table 1. $\underline{(14 K))}$.

What remains to be done is to refine the analysis. A challenge is to find a way of representing conflict and contradiction.

\section{Conclusion}

A major difficulty in object-oriented design is the initial identification of objects (Coad and Yourdon 1991). Activity theory provides guidelines for this process. It also suggests what the affordances of objects should be.

Ecological Interface Design suggests that the goal of interface design is to correctly model the affordances of the environment, taking account of the unique perceptual and diagnostic abilities of human operators (Vicente and Rasmussen 1992). The abstraction hierarchy provides the means to represent affordances. Gibson was hampered in his attempts to resolve the problem of indirect perception by his static conception of the relationship between the organism and the environment (Noble 1991). Activity Theory suggests that this relationship is never static, but is always in the process of being recreated. Objects in the world come into existence only as a result of the subject's interactions with the world. Objects reify processes. Objects only exist because they have meaning. They acquire meaning through collaborative action. Thus the task for the designer of the interface to an organizational electronic text is how to provide the tools that enable users to create meaning (objects). Specifically, how do you represent culture in the electronic text so that its creation becomes a conscious act?

\section{References}

Argote, L. 1993. Group and organizational learning curves: individual, system and environmental components. British Journal of Social Psychology 32 31-51. 
Basseches, M. 1984. Dialectical thinking and adult development. Norwood: Ablex.

Beniger, J. R. 1986. The control revolution: Technological and economic origins of the information society. Cambridge, Mass: Harvard University Press.

Boland, R. J., Maheshwari, A. K., and D. Te'eni. (1992). Sharing perspectives in distributed decision making. In: CSCW'92 Proceedings, pp. 306-313.

Boland, R. J., Tenkasi, R. V., and Te'eni, D. (1994). Designing information technology to support distributed cognition. In: Organization Science, 5(3), pp. 456-475.

Boulter, J. D. 1984. Turing's man: Western culture in the computer age. North Carolina University Press.

Brown, A. L. 1982. Design experiments: theoretical and methodological challenges in creating complex interventions in classroom settings. The Journal of the Learning Sciences 2(2) 141-178.

Brown, J. S. (1991). Research that reinvents the corporation. In: Harvard Business Review, 69(1), 102-111.

Carlson, D. A. and Ram, S. 1990. HyperIntelligence: The next frontier. Communications of the ACM 33(3) 311-321.

Coad, P.and Yourdon, E. 1991. Object Oriented Design. Engelwood Cliffs, N. J.: Yourdon Press.

Connerton, P. 1989. How societies remember. Cambridge: Cambridge University Press.

Engeström, Y. (1987). Learning by expanding: an activity theoretical approach to developmental research. Helsinki: Orienta-Konsultit Oy.

Engeström, Y. 1990. Learning, working and imagining: twelve studies in activity theory. Helsinki: Orienta-Konsultit Oy.

Favorin, M. and K. Kuutti (1994) To support learning at work by making work visible through information technology: an activity theory approach. In: J. J. Levonen and M. T. Tukiainen (Eds.), Proc. of the Interdisciplinary Workshop on 
Complex Learning in Computer Environments: Technology in School, University, Work, and Life-Long Education (CLCE94).

Gibson, J. J. 1979. The ecological approach to visual perception. Boston: Houghton-Mifflin.

Gooding, C. 1995. Boosting sales with the information warehouse. Financial Times: IT Software at Work, March 115.

Goody, J. 1977. The domestication of the savage mind. Cambridge, England: Cambridge University Press.

Heydebrand, W. 1989. New organizational forms. Work and Occupations, 16(3) 323-357.

Hirschhorn, L. 1984. Beyond mechanization: Work and technology in a postindustrial age. Cambridge, Mass: The MIT Press.

Holt, G. R. and Morris, A. W. 1993. Activity theory and the analysis of organizations. Human Organization 52(1) 97-109.

Hoskin, K. W. and R. H. Macve. 1986. Accounting and the examination: a genealogy of disciplinary power. Accounting, organizations and society 11(2) 105-136.

Huber, G. P. (1990) A theory of the effects of advanced information technologies on organizational design, intelligence, and decision making. In: Academy of Management Review 15(1) 47-71.

Jones, K. 1984. Conflict and Change in Library Organizations: people, power, and service. Clive Bingley, London.

Kim, D. H. (1993). The link between individual and organizational learning. In: Sloan Management Review. Fall 1993. pp. 37-50.

Kuutti, K. and Arvonen, T. (1992). Identifying potential CSCW applications by means of activity theory concepts: a case example. CSCW 92 Proceedings. Kuutti, K. and Virkkunen, J. (1995) Organizational memory and learning network organization: the case of Finnish Labour Protection Inspectors. To be published in the Proceedings of the HICSS-28, Hawaii, January 3-6, 1995. 
Lave, J. 1988. Cognition in practice: Mind, mathematics and culture in everyday life. Cambridge: CUP.

Meyer, B. 1990. The new culture of software development. Journal of Object Oriented Programming, November/December 76-81.

Moulin, B. 1990. Strategic planning for expert systems. IEEE Expert. April 69-75. McLuhan, M. (1964). Understanding media: the extensions of man. New York: McGraw-Hill.

Noble, W. 1991. Ecological realism and the fallacy of 'objectification'. In: Against Cognitivism: Alternative Foundations For Cognitive Psychology, ed. A. Still and A. Costall. Brighton: Harvester- Wheatsheaf.

Ong, W. J. (1982). Orality and literacy: the technologizing of the word. London: Methuen \& Co. Ltd.

Piore, M. and Sabel, C. (1984). The second industrial divide: possibilities for prosperity. New York: Basic Books.

Rasmussen, J., Pejtersen, A. M., and Goodstein, L. P. 1994. Cognitive Systems Engineering. Chichester: Wiley.

Rogoff, B. (1984). Introduction: thinking and learning in social context. In: Everyday cognition: its development in social context. Harvard University Press, Harvard, MA. 1-8.

Schein, E. H. 1985. Organizational culture and leadership. San Francisco: Jossey-Bass.

Scribner, S.and Cole, M. 1981. The psychology of literacy. Cambridge, MA: Harvard University Press.

Vicente, K. J., and J. Rasmussen (1992) Ecological Interface Design: Theoretical Foundations. In: IEEE Transactions on Systems, Man, and Cybernetics, 22(4), 589-606.

Whyte, W. F. 1991. Social theory for action: how individuals and organizations learn to change. London: Sage.

Young, M. F. (1993). Instructional design for situated learning. In: ETR\&DEducational Technology Research \& Development 41(1) 43-58. 
Zuboff, S. 1988. In the age of the smart machine: the future of work and power. London: Heinemann. 